\title{
Sensory Quality of Chhana Based Cheese Spread from Cow Milk
}

\author{
Alok Rai*, M. P. S. Yadav, Shikha Singh and Samar Jeet Singh \\ Department of AH \& Dairying, C. S. Azad University of Agriculture and Technology, \\ Kanpur UP - 208002, India \\ *Corresponding author
}

\section{Keywords}

Cow milk chhana,

Cheese,

Citric acid, Salt

\section{Article Info}

Accepted:

18 March 2020

Available Online:

10 April 2020

\section{A B S T R A C T}

The present investigation entitled "Preparation of chhana based cheese spread from cow milk" was conducted in the laboratory of Department of A.H. \& Dairying (Dairy Technology), C.S.A University of Agriculture and technology Kanpur. In the experiment Cow milk in the ratio $(95: 5,90: 10,85: 15,80: 20)$ four levels of cheese, tow level of salt (1\% and 2\%), one level of coagulant (citric acid) and four storage periods ( $0,10,20$ and 30 days) were taken for preparation of chhana spread. Five physical attributes are flavor, body and texture, colour and appearance, spreadibility and over-all acceptability. The study revealed that the physical quality of chhana spread from cow milk coagulated by citric acid with 2 per cent salt level at 0 day storage period was found better as compared to other. It was also concluded from the present investigation that this chhana spread can be stored successfully for 30 days without any significant deterioration at $5^{\circ} \mathrm{C}$. The combination of chhana spread and cheese in ratio of 85:15 was found best considering physico properties.

\section{Introduction}

India has emerged as the largest milk producer in the world with a record production level of 176.30 million tons during 2017-18.and the importance of milk and milk product in India has been recognized since Vedic times (five thousand years ago). The significant portion of milk produced in India is convered into a variety of indigenous milk products. Among milk products, chhana is gaining momentum in its production and consumption. Chhana is heat and acid coagulated Indigenous milk products which forms the base of several popular Indian sweets like Rasogulla, Sandesh, Rasmalai and Chumchum etc.

It is also used as base material for the preparation of large number dishes. It originated in eastern part of the country particularly from west Bengal, but now a day it is also popular in north western region of India. 
Chhana or paneer means the product obtained from cow milk by precipitation with sour milk, lactic acid or citric acid. It shall not contain more than 70 per cent moisture and the milk fat content shall not be less than 50 per cent of the dry matter.

Food and nutritive value of Chhana is fairly high as it contains almost all the protein present in milk besides quantity of minerals and vitamins. It possesses a nutty flavor with slightly sour and sweet taste which makes it palatable to Indian palate.

It is an ideal food for expectant and nursing mothers, infants, growing children, adolescents and adults. Being rich source of animal protein, it is a good source of all the essential amino acids to the vegetarians. Its fat content renders the Fat Soluble Vitamins $\mathrm{A}$ and D, essential fatty acid (Linoleic, linolenic and arachedonic acid) and energy.

With its high protein and low sugar content, it is highly recommended to the diabetic patients. It has also particular food value for those who possess the problem of milk intolerance.

Chhana retains about 90 percent of fat and protein, 50 per cent lactose of the original milk. The energy value of cow chhana ranges from 2866 to 3748 calories per $\mathrm{kg}$. And chhana also retain appreciable proportion of fat solution vitamins like A and D (Ray and De, 1953).

Recently a spread has been developed from chhana which has pleasant taste and comparatively less animal fat and is liked very much over other spreads for its nutty flavor. At present, there are mainly two types of spreads available in the market, namely butter and cheese spreads. These are usually used along with bread in the breakfast.

\section{Materials and Methods}

Cow milk was obtained from university dairy situated at Kanpur campus for entire experiment. Chhana spread manufacturing technology from cow milk was observed on the basis of various parameters under study and final product was subjected for the evaluation of sensory physico qualities.

\section{Preparation of channa}

The cow milk was heated in karahi; over an open fire to $70^{\circ} \mathrm{C}$. The milk was slowly stirred by a ladle during heating to avoid burning. When temperature of milk reached $70^{\circ} \mathrm{C}$ then coagulation with $1 \%$ solution of citric acid was added to the milk slowly with stirring till the complete coagulation took place.

After coagulation the stirring was stopped and contents were poured over a piece of clean muslin cloth for straining of whey. After the draining of whey chhana was collected and weighed.

\section{Preparation of channa based spread}

After weighting the channa the common salt at $1 \%, 2 \%$ and cheese level $5 \%, 10 \%, 15 \%$, $20 \%$ was mixed with the help of mixer. Finally, chhana spread was collected and packed in plastic cups (Figure 1).

\section{Results and Discussion}

Sensory evaluation of chhana spread was done on the basis of organoleptic tests by panel of five judges of department of Animal husbandry and dairying, Chandra Shekhar Azad University of Agriculture and Technology, Kanpur.

The judges evaluated the sample taking in the consideration of flavor, body and texture, colour and appearance, spreadability, and 
over all acceptability of chhana spread. The point hedonic scale was used for evaluation of product for sensory characteristics. The results and discussion of the present investigation have been summarized in the following appropriate heads.

\section{Flavor}

The maximum (5.43) flavor score was found in A2 samples, while minimum (5.01) in A1 sample. The result varied significantly. The effect of cheese level of flavor score, it was observed that maximum (5.68) score in B3 sample, followed by B2 (5.21) and minimum (4.85) was noted in B4 sample. The result varied significantly. So for as the different storage periods, In case of storage periods (C) the maximum (8.26) flavor score was observed in fresh sample and minimum score(2.79) in C4 sample. The result varied significantly.

Among the treatment combination of $\mathrm{AxB}$, the maximum score (5.93) was noted in A2B3 followed by $\mathrm{A} 1 \mathrm{~B} 3$ and minimum (4.65) in A1B4 sample. In case of $\mathrm{AxC}$, maximum score (8.50) was noted in A2C1 sample and minimum in $\mathrm{A} 1 \mathrm{C} 4$. Among the interactions of $\mathrm{BxC}$, maximum score (8.80) was noted in $\mathrm{B} 3 \mathrm{C} 1$ followed by $\mathrm{B} 2 \mathrm{C} 1$, while minimum score (2.30) noted in B4C4 samples. The result varied non-significant.

Among the treatment combination of salt levels, cheese percentage and storage periods $(\mathrm{AxBxC})$, it was observed that the maximum score (9.00) in A2B3C1 samples followed by $\mathrm{A} 1 \mathrm{~B} 3 \mathrm{C} 1$, while minimum score (2.10) was noted in A1B4C4 sample. The result varied non-significant.

\section{Body and Texture}

The maximum (5.36) body and texture score was found in A2 samples, while minimum
(4.95) in A1 sample. The result varied significantly.

The effect of cheese level of body and texture score, it was observed that maximum (5.43) score in B3 sample, followed by B2 (5.27) and minimum (4.85) was noted in B4 sample. The result varied significantly.

So for the different storage period maximum (8.22) body and texture score was observed in fresh sample and minimum score(2.70) in $\mathrm{C} 4$ sample. the result varied significantly.

Among the treatment combination effect of $\mathrm{AxB}$, the maximum score (5.65) was noted in A2B3 followed by A1B2 and minimum (4.65) in $\mathrm{A} 1 \mathrm{~B} 4$ sample. In case of $\mathrm{AxC}$, maximum score (8.45) was noted in $\mathrm{A} 2 \mathrm{C} 1$ sample and minimum in $\mathrm{A} 1 \mathrm{C} 4$. Among the interactions of $\mathrm{BxC}$, maximum score (8.50) was noted in $\mathrm{B} 3 \mathrm{C} 1$ followed by $\mathrm{B} 2 \mathrm{C} 1$, while minimum score (2.40) noted in B2C4 samples

Among the treatment combination of salt levels, cheese percentage and storage periods $(\mathrm{AxBxC})$, it was observed that the maximum score (8.70) in A2B3C1 samples followed by A223C1, while minimum score (2.20) was noted in A1B4C4 sample. The result varied non-significant.

\section{Colour and appearance}

The maximum (5.25) colour and appearance score was found in A2 samples, while minimum (4.85) in A1 sample. The result varied significantly.

The effect of cheese level of colour and appearance score, it was observed that maximum (5.35) score in B3 sample, followed by B2 (5.15) and minimum (4.75) was noted in B4 sample. The result varied significantly. 
So for as the different storage period (C) the maximum (8.10) colour and appearance score was observed in fresh sample (C1) and minimum score (2.60) in $\mathrm{C} 4$ sample. The result varied significantly. Among the treatment combination of $\mathrm{AxB}$, the maximum score (5.55) was noted in A2B3 followed by A2B2 and minimum (4.55) in A1B4 sample. In case of $\mathrm{AxC}$, maximum score (8.30) was noted in $\mathrm{A} 2 \mathrm{C} 1$ sample and minimum in A1C4. Among the interactions of $\mathrm{BxC}$, maximum score (8.40) was noted in $\mathrm{B} 3 \mathrm{C} 1$ followed by $\mathrm{B} 2 \mathrm{C} 1$, while minimum score (2.33) noted in B4C4 samples.. The result varied non-significant

Among the treatment combination of salt levels, cheese percentage and storage periods $(\mathrm{AxBxC})$, it was observed that the maximum score (8.60) in $\mathrm{A} 2 \mathrm{~B} 3 \mathrm{C} 1$ samples followed by A2B2C1, while minimum score (2.10) was noted in A1B4C4 sample. The result varied non-significant.

\section{Spreadability}

The maximum (5.17) flavor score was found in A2 samples, while minimum (4.76) in A1 sample. The result varied significantly.

The effect of cheese level of spreadability score, it was observed that maximum (5.27) score in B3 sample, followed by B2 (5.07) and minimum (4.65) was noted in B4 sample. The result varied significantly. So for as the different storage period the maximum (8.05) spreadability score was observed in fresh sample and minimum score (2.52) in $\mathrm{C} 4$ sample. The result varied significantly.

Among the treatment combination of $\mathrm{AxB}$, the maximum score (5.50) was noted in A2B3 followed by $\mathrm{A} 2 \mathrm{~B} 2$ and minimum (4.45) in A1B4 sample. In case of $\mathrm{AxC}$, maximum score (8.30) was noted in $\mathrm{A} 2 \mathrm{C} 1$ sample and minimum in $\mathrm{A} 1 \mathrm{C} 4$. Among the interactions of
$\mathrm{BxC}$, maximum score (8.40) was noted in $\mathrm{B} 3 \mathrm{C} 1$ followed by $\mathrm{B} 2 \mathrm{C} 1$, while minimum score (2.20) noted in B4C4 samples. The result varied non-significant.

Among the treatment combination of salt levels, cheese percentage and storage periods $(\mathrm{AxBxC})$, it was observed that the maximum score (8.70) in A2B3C1 samples followed by A2B2C1, while minimum score (2.20) was noted in A1B4C4 sample. The result varied non-significant.

\section{Over all acceptability}

The maximum (5.36) over all acceptability score was found in A2 samples, while minimum (4.96) in A1 sample. The result varied significantly. The effect of cheese level of overall acceptability score, it was observed that maximum (5.47) score in B3 sample, followed by B2 (5.25) and minimum (4.85) was noted in B4 sample. At regard the different level of storage period the maximum over all acceptability score of chhana spread (8.22) was noted in $\mathrm{C} 1$ and minimum over all acceptability was found (2.72) in $\mathrm{C} 4$. The result varied significantly.

Among the treatment combination of $\mathrm{AxB}$, the maximum score (5.70) was noted in A2B3 followed by $\mathrm{A} 2 \mathrm{~B} 2$ and minimum (4.85) in $\mathrm{A} 2 \mathrm{~B} 4$ sample. In case of $\mathrm{AxC}$, maximum score (8.45) was noted in $\mathrm{A} 2 \mathrm{C} 1$ sample and minimum in $\mathrm{A} 1 \mathrm{C} 4$. Among the interactions of $\mathrm{BxC}$, maximum score (8.60) was noted in $\mathrm{B} 3 \mathrm{C} 1$ followed by $\mathrm{B} 2 \mathrm{C} 1$, while minimum score (2.40) noted in B4C4 samples. The result varied non-significantly. Among the treatment combination of salt levels, cheese percentage and storage periods $(\mathrm{AxBxC})$, it was observed that the maximum score (8.90) in A2B3C1 samples followed by A2B2C1, while minimum score (2.20) was noted in A1B4C4 sample. The result varied nonsignificant. 


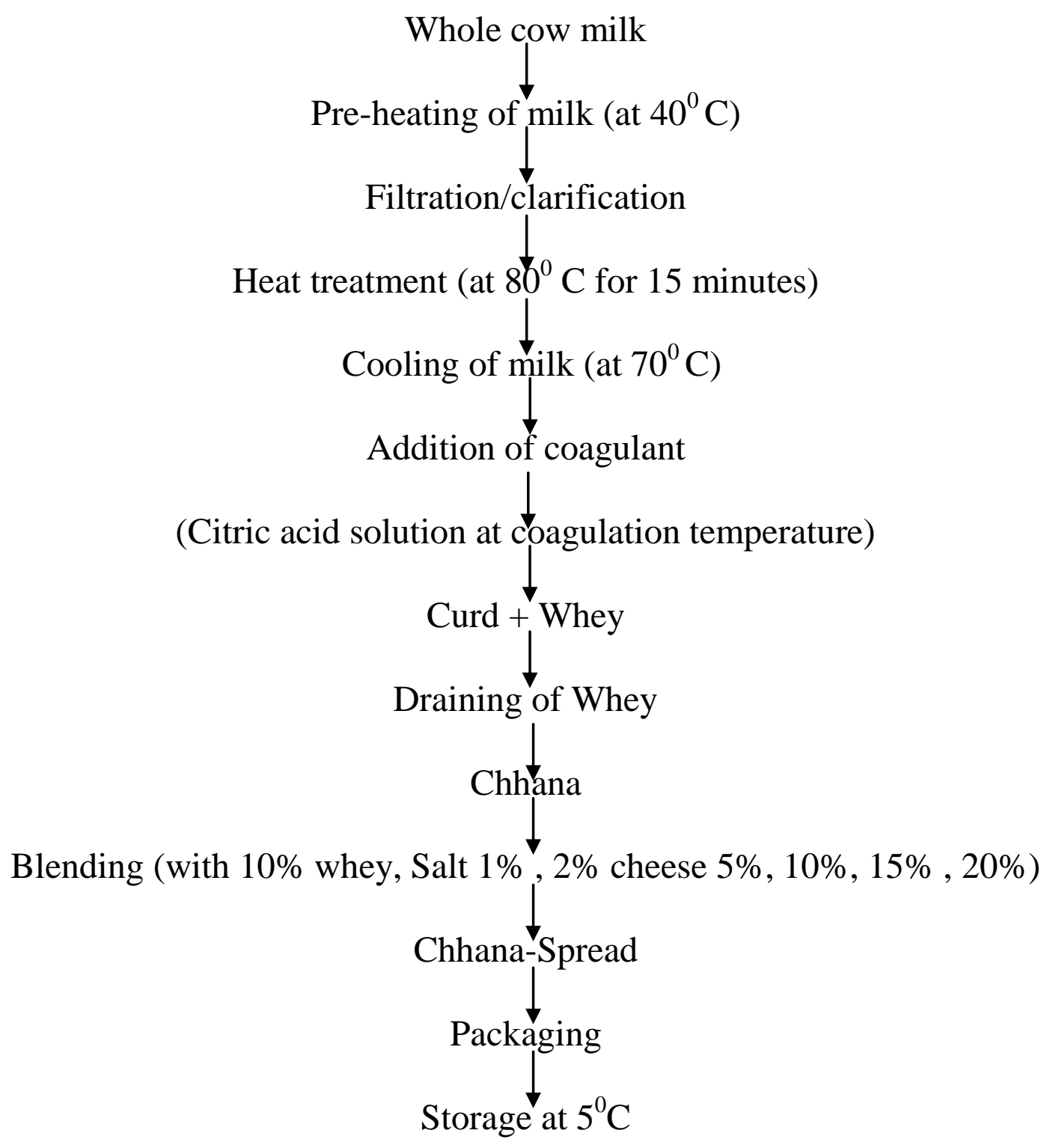

Figure.1 Manufacturing procedure of Chhana spread

Channa possesses a nutty flavor with slightly sour and sweet taste which makes it palatable to Indian palate. It possesses beneficial ingredients which consumption should be increased Other than this Channa contain flavor-active compounds.

Considering the major role of spread in daily diet and nutrition, it is surprising that the scientific literature of factors influencing sensory quality of spread is rather limited. So, a spread that has been developed from chhana has pleasant taste and comparatively less animal fat and is liked very much over other spreads for its nutty flavor.

\section{References}

Chopde, R.L., Chilgunde, S.N., Zanjad, P.N., Ambadkar, R.K. and Baig, M.I. (2005). Comparative studies on quality of chhana prepared from buffalo milk and cowmilk. Journal of Bombay Veterinary College. 13 1/2, 87-90. 
De, S. and Ray, S.C. (1953). Studies on the indigenous method of chhana making. Indian J. Dairy Science. 7(3): 113.

Ray, S.S. and De, S. (1953). Indigenous milk products of India-3: Chhana. Indian Dairyman. 4(1): 15-18.

Sanjay Kumar Dwivedi, H. B. Yadav, S. P. and Yadav, R. N. (2007). Use of chemical and herbal coagulants in Chhana production from cow milk.
Progressive Research; 2(1/2): 150

Siddiqui, T.F., Zanjad, P.N., Raziuddin, M. and Ambadkar, R.K. (2006). Process standardization of buffalo milk chhana. Veterinary World. 4 (10), 295-298.

Sindhu, J. S.andPatil, G. R.(2004).Effect of alteration of salt balance of cow milk on texture of chhana. Indian Journal of Dairy Science; 57(1):17-20.

\section{How to cite this article:}

Alok Rai, M. P. S. Yadav, Shikha Singh and Samar Jeet Singh. 2020. Sensory Quality of Chhana Based Cheese Spread from Cow Milk. Int.J.Curr.Microbiol.App.Sci. 9(04): 2320-2325. doi: https://doi.org/10.20546/ijcmas.2020.904.278 